Laser Chem., 1999, Vol. 19, pp. 299-303

Reprints available directly from the publisher Photocopying permitted by license only
(C) 1999 OPA (Overseas Publishers Association) N.V. Published by license under the Harwood Academic Publishers imprint, part of The Gordon and Breach Publishing Group.

\title{
TRANSIENT ABSORPTION AND RAMAN STUDIES ON EXCIPLEX FORMATION DYNAMICS OF PHOTOEXCITED Cu(II)(TMpy-P4) WITH SYNTHETIC POLYNUCLEOTIDE
}

\author{
SAE CHAE JEOUNG, HYO SOON EOM and DONGHO KIM* \\ Spectroscopy Lab. and Center for Ultrafast Optical Properties \\ Characterization, Korea Research Institute of Standards \\ and Science,Taejon 305-600, Korea
}

(Received 7 April 1997)

Exciplex formation dynamics of photoexcited copper(II) tetrakis (4- $N$-methylpyridyl) porphyrin $(\mathrm{Cu}(\mathrm{II})(\mathrm{TMpy}-\mathrm{P} 4))$ with added poly(dA-dT $)_{2}$ and poly $(\mathrm{dG}-\mathrm{dC})_{2}$ has been investigated by using femtosecond transient absorption and nanosecond and picosecond transient Raman spectroscopic methods. It was observed that the decay time constant of the exciplex is strongly dependent on the polynucleotide and has a strong correlation with the appearance of new transient Raman bands.

Keywords: $\mathrm{Cu}(\mathrm{II})(\mathrm{TMpy}-\mathrm{P} 4)$; polynucleotide; transient Raman; transient absorption; exciplex

Previously, numerous investigations [1] have been carried out to elucidate a peculiar photodynamics for copper(II) porphyrins as well as the interaction mechanism of $\mathrm{Cu}(\mathrm{II})(\mathrm{TMpy}-\mathrm{P} 4)$ with synthetic polynucleotides. In this work, we present the results of the comparative studies on the photodynamics of $\mathrm{Cu}(\mathrm{II})(\mathrm{TMpy}-\mathrm{P} 4)$ in two different polynucleotides, poly $(\mathrm{dA}-\mathrm{dT})_{2}$ and poly $(\mathrm{dG}-\mathrm{dC})_{2}$, investigated by using the femtosecond transient absorption and transient Raman spectroscopic techniques.

\footnotetext{
* Corresponding author.
} 
With an addition of poly(dA-dT $)_{2}$ concentration, the transient absorption decay profiles measured in photoexcited $\mathrm{Cu}$ (II)(TMpy-P4) give only the slow component ( $\tau \sim 2.3 \mathrm{~ns})$ without any rise component (Fig. 1). The nanosecond transient Raman spectra (Fig. 2) and

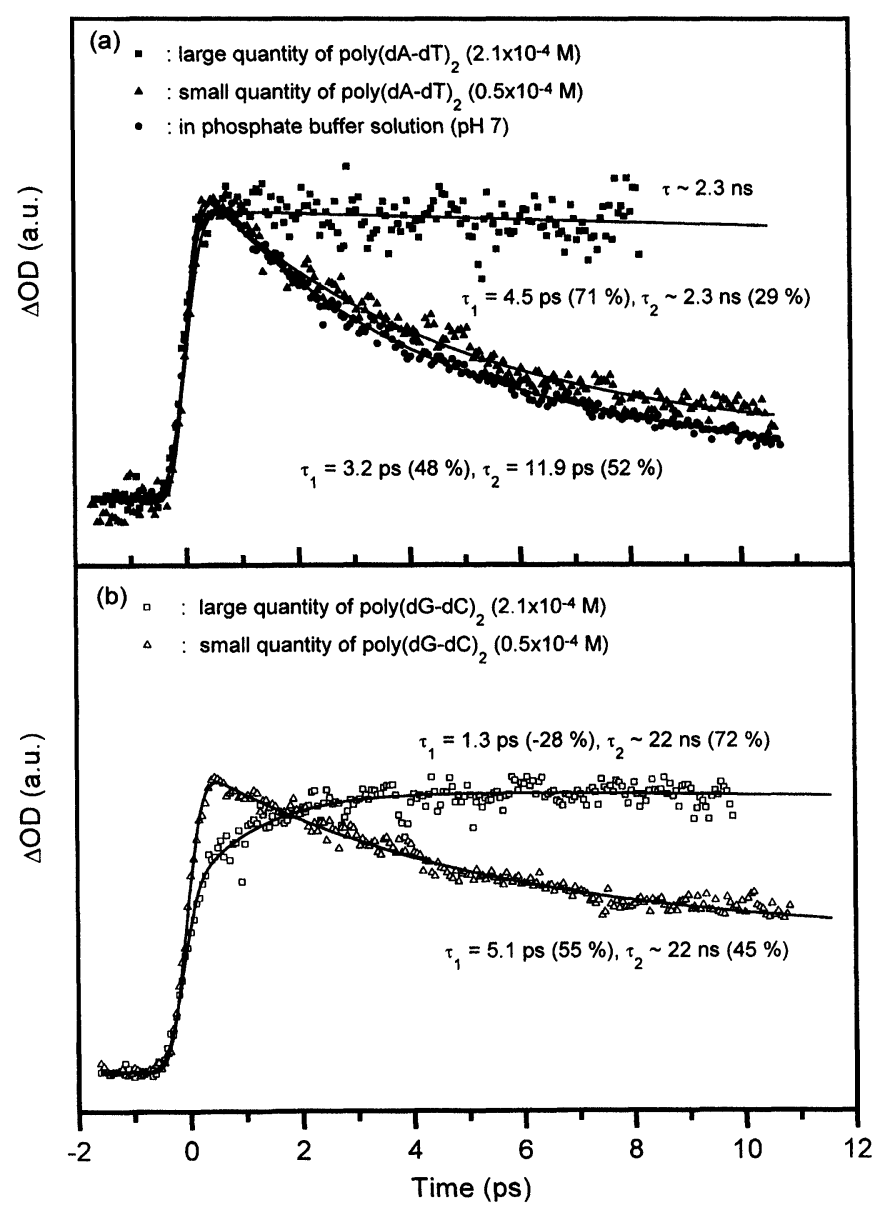

FIGURE 1 The decay profiles of photoinduced absorbance changes of $\mathrm{Cu}(\mathrm{II})(\mathrm{TMpy}-$ P4) in aqueous solution and mixed with poly $(\mathrm{dA}-\mathrm{dT})_{2}$ (a) and poly $(\mathrm{dG}-\mathrm{dC})_{2}$ (b) in phosphate buffer $(\mathrm{pH}=7)$ monitored at $460 \mathrm{~nm}$. The average power of the pump pulse at $400 \mathrm{~nm}$ is about $8 \mathrm{~mW}$ at $1 \mathrm{kHz}$ repetition rate. The lifetime of the long-lived component shown in (a) $(\tau \sim 2.3 \mathrm{~ns})$ was measured by the moving the optical delay line in the long range. The lifetime of the long-lived component $(\tau \sim 22 \mathrm{~ns})$ was taken from the reported values (Hudson, B. P., Sou, J., Berger, D. J. and McMillin, D. R. (1992). J. Am. Chem. Soc., 114, 8997) based on the time-resolved emission measurements. 
(a)

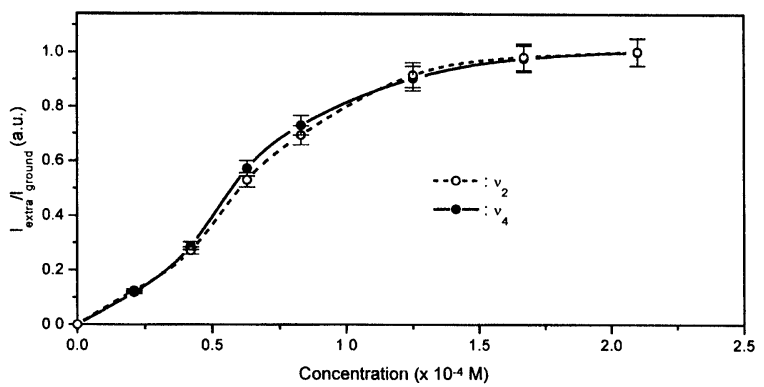

(b)

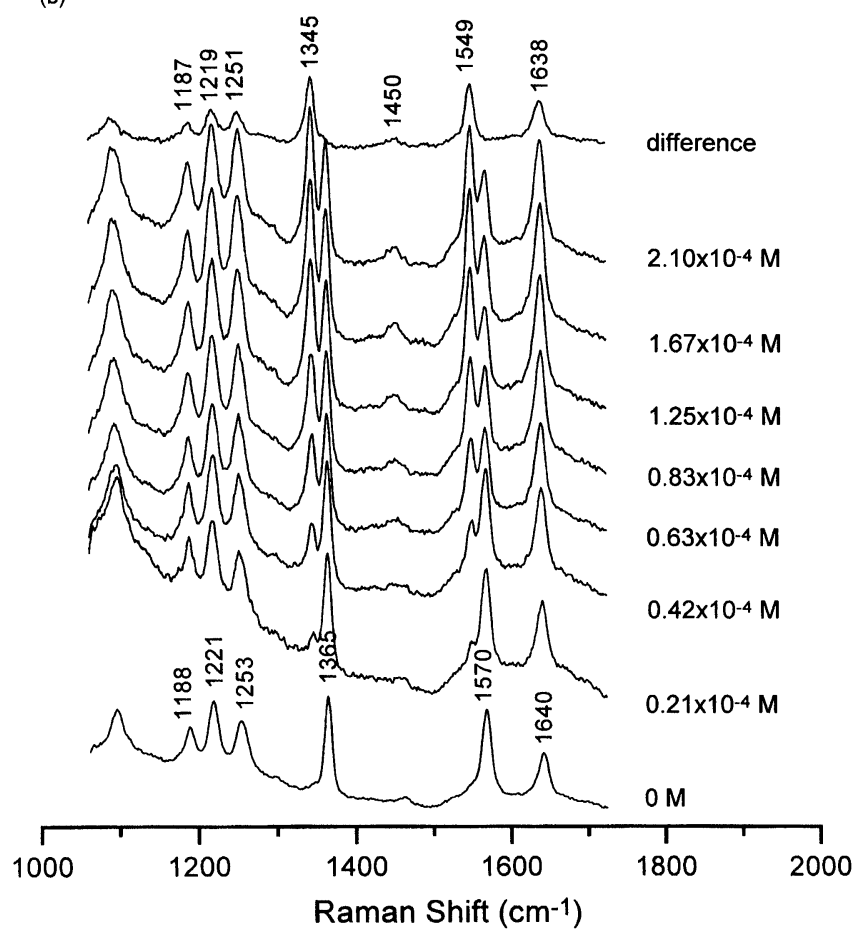

FIGURE 2 The series of transient RR spectra of $\mathrm{Cu}(\mathrm{II})(\mathrm{TMpy}-\mathrm{P} 4)$ mixed with poly $(\mathrm{dA}-\mathrm{dT})_{2}$. The porphyrin concentration and the laser power were kept lower than $10^{-5} \mathrm{M}$ and $1 \mathrm{~mJ}$, respectively. (a) Measured intensity ratios of extra Raman bands to the corresponding ground state ones as a function of added poly $(\mathrm{dA}-\mathrm{dT})_{2}$. (b) The series of transient Raman spectra of $\mathrm{Cu}(\mathrm{II})(\mathrm{TMpy}-\mathrm{P} 4)$ aqueous solution with increasing the relative portion of the synthetic polynucleotide upon photoexcitation at $416 \mathrm{~nm}$. The top spectrum denotes the difference Raman spectrum. 
transient absorption decay profiles of $\mathrm{Cu}(\mathrm{II})(\mathrm{TMpy}-\mathrm{P} 4)$ mixed with poly $(\mathrm{dA}-\mathrm{dT})_{2}$ clearly indicate that polynucleotides and water molecules compete each other in the exciplex formation with photoexcited $\mathrm{Cu}(\mathrm{II})(\mathrm{TMpy}-\mathrm{P} 4)$. In other words, the added poly(dA-dT) $)_{2}$ to the aqueous solution form the exciplex with photoexcited copper(II) porphyrins more efficiently than water molecules.

On the other hand, upon increasing the relative concentration of poly(dG-dC $)_{2}$ in $\mathrm{Cu}(\mathrm{II})(\mathrm{TMpy}-\mathrm{P} 4)$ aqueous solution, the trace of the

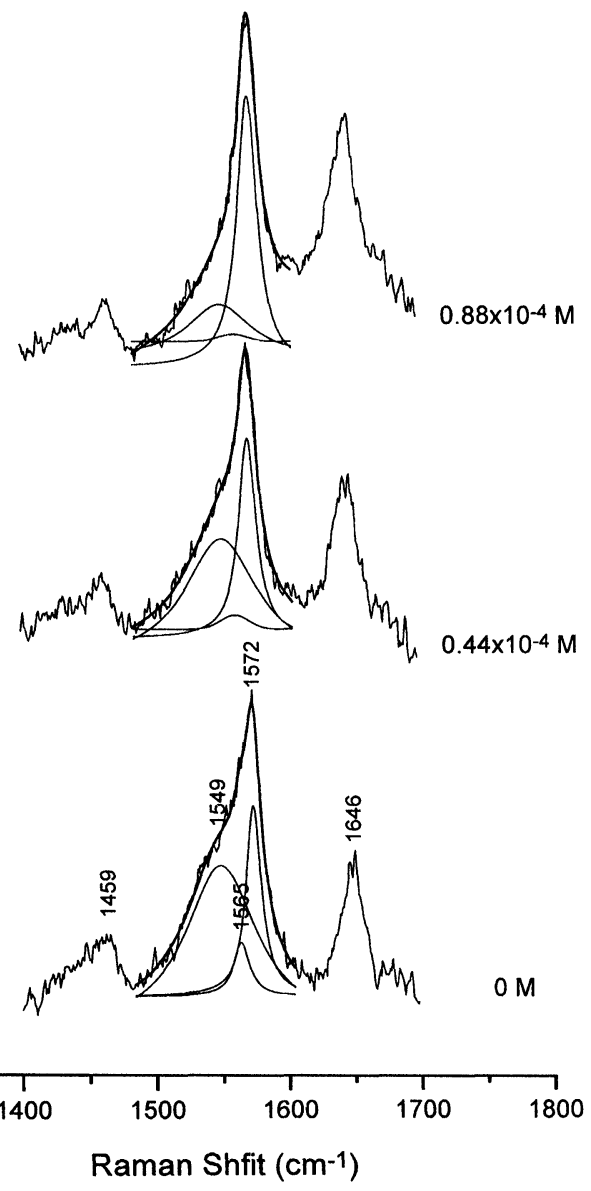

FIGURE 3 The series of picosecond transient RR spectra of $\mathrm{Cu}(\mathrm{II})(\mathrm{TMpy}-\mathrm{P} 4)$ mixed with poly $(\mathrm{dG}-\mathrm{dC})_{2}$ with increasing the concentration of the polynucleotide with an excitation at $436 \mathrm{~nm}$. 
exciplex formation between photoexcited $\mathrm{Cu}(\mathrm{II})(\mathrm{TMpy}-\mathrm{P} 4)$ and water molecules disappears in the picosecond transient Raman spectra (Fig. 3). In addition, the transient absorption of $\mathrm{Cu}(\mathrm{II})(\mathrm{TMpy}-\mathrm{P} 4)$ mixed with poly(dG-dC) $)_{2}$ exhibits a rise component of 1.3 ps in addition to the very slow decay component $(\tau \sim 22 \mathrm{~ns})$. The long-lived component ( $\tau \sim 22 \mathrm{~ns}$ ) obtained by time-resolved photoluminescence for $\mathrm{Cu}(\mathrm{II})(\mathrm{TMpy}-\mathrm{P} 4)$ in poly $(\mathrm{dG}-\mathrm{dC})_{2}$ is probably responsible for the decay from the tripmultiplet $\left(\pi, \pi^{*}\right)$ states of $\mathrm{Cu}(\mathrm{II})$ (TMpy-P4) (Fig. 1). The fast rise-component might be attributable to the short-lived unstable exciplex between photoexcited $\mathrm{Cu}$ (II)(TMpy-P4) and nitrogen atom of cytosine residue in the intercalation site of ploy(dG-dC $)_{2}$ or the formation time of the tripmultiplet states from the initially excited singlet state of $\mathrm{Cu}(\mathrm{II})(\mathrm{TMpy}-\mathrm{P} 4)$. In conclusion, the change of the added polynucleotide from poly $(\mathrm{dA}-\mathrm{dT})_{2}$ to poly $(\mathrm{dG}-\mathrm{dC})_{2}$ induces a drastic alteration in the exciplex formation dynamics as well as the overall decay process of photoexcited $\mathrm{Cu}(\mathrm{II})(\mathrm{TMpy}-\mathrm{P} 4)$ [2].

\section{Acknowledgements}

This work has been financially supported by Creative Research Initiatives of the Ministry of Science and Technology of Korea.

\section{References}

[1] Kruglik, S. G., Galievsky, V. A., Chirvony, V. S., Apanasevich, P. A., Ermolenkov, V. V., Orlovich, V. A., Chinsky, L. and Turpin, P.-Y. (1995). J. Phys. Chem., 99, 5732.

[2] Slama-Schwork, A. and Lehn, J.-M. (1990). Biochemistry, 29, 7895. 